\title{
Cytoreductive surgery and hyperthermic intraperitoneal chemotherapy for treatment of peritoneal carcinomatosis: our initial experience of implementation and detailed technique
}

\author{
Talgat Uskenbayev, Altay Kerimkulov, \\ No 1 Surgery Department, National Research Center \\ for Oncology and Transplantatology, Nur-Sultan city, \\ Republic of Kazakhstan
}

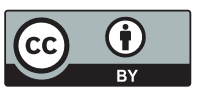

This work is licensed under a Creative Commons Attribution 4.0 Creative Commons Attrit
International License

\section{Received: 2019-04-25}

Accepted: 2018-06-13

UDC: 616.1

\section{J Clin Med Kaz 2019;2(52):50-58}

Corresponding Author: Altay Kerimkulov, No 1 Surgery Department, National Research Center for Oncology and Transplantatology, Nur-Sultan, Republic of Kazakhstan.

E-mail: altay.kerimkulov@gmail.com

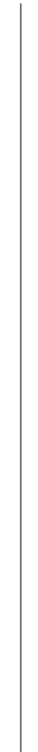

\begin{abstract}
Objective: The aim of this study is to present our initial implementation experience in peritoneal carcinomatosis treatment and the technical details of cytoreductive surgery and hyperthermic intraperitoneal chemotherapy in the light of current literature.

Material and methods: Data of 7 consecutive patients who were treated with cytoreductive surgery and hyperthermic intraperitoneal chemotherapy for peritoneal carcinomatosis in the National Research Center for Oncology and Transplantology, between October 2016 and December 2018 were retrospectively reviewed. Treatment indication and management were evaluated at the multidisciplinary oncology council. All patients underwent cytoreductive surgery and hyperthermic intraperitoneal chemotherapy with the aim of complete cytoreduction. Patients with unresectable disease and/or palliative surgery were excluded from analysis. Perioperative complications were classified according to Clavien-Dindo classification, and hyperthermic intraperitoneal chemotherapyrelated side effects were identified using National Cancer Institute Common Terminology Criteria for Adverse Events (CTCAE) criteria. Demographic, clinical and histopathological data of the patients were analyzed.

Results: The mean age was 47 (30-62). Three patients were female. The origin of peritoneal carcinomatosis was colorectal cancer in 3 patients, ovarian cancer in 2 patients and pseudomyxoma peritonei in 2 patients. The mean Peritoneal Carcinomatosis Index was 17 (3-32), with a mean operative time of 517 (366-710) minutes. Perioperative morbidity and mortality were observed in $2(28,5 \%)$ and one patient (14.2\%), respectively. During a mean follow up of 9,6 (3-26) months, overall and disease-free survival rates were $85,7 \%$ and $83,3 \%$, respectively. One patient with colorectal cancer (after 12 months) had retroabdominal recurrence. The remaining patients are being followed-up without any recurrence.
\end{abstract}

Conclusion: Cytoreductive surgery and hyperthermic intraperitoneal chemotherapy have favorable results in the treatment of patients with peritoneal carcinomatosis. Compatible with the literature, surgical outcomes of the presented series are encouraging for this treatment modality. Careful perioperative evaluation, proper patient selection and multidisciplinary approach are essential for success in curative treatment of peritoneal carcinomatosis.

Keywords: Peritoneal carcinomatosis, cytoreductive surgery, hyperthermic intraperitoneal chemotherapy 


\section{ПЕРИТОНЕАЛДЫ КАНЦЕРОМАТОЗ ЕМІНДЕ КОЛДАНЫЛАТЫН МАКСИМАЛДЫ ЦИТОРЕДУКТИВТІ ОТА МЕН ГИПЕРТЕРМИЯЛЫҚ ИНТРАПЕРИТОНЕАЛДЫ ХИМИОТЕРАПИЯ: АЛҒАШҚЫ ЕНДІРУ ТӘЖІРИБЕСІ МЕН ТЕХНИКАЛЫК ӘДІСТЕМЕСІ}

Ускенбаев Т.А., Керимкулов А.К., Мукажанов А.К., Мамлин М.А., Калиев Р.Б.

Хирургия бөлімшесі, Ұлттық онкология және трансплантология ғылыми орталығы, Нұр-Сұлтан қаласы, Қазақстан Республикасы

\section{тұЖЫРЫМДАМА}

Мақсаты: Мақаланың мақсаты перитонеальды канцероматозы бар науқастарға жасалған максимальды циторедуктивті ота мен гипертермиялық интраперитонеалды химиотерапияны ендіру тәжірибесі мен нәтижелерін техника әдістемесі және ғылыми әдебиеттегі мәліметтерімен бірге ұсыну.

Материалдар мен әдістер: Ұлттық онкология және трансплантология ғылыми орталығында 2016 жылдың қазанынан 2018 жылдың желтоқсаны аралығында максимальды циторедуктивті ота мен гипертермиялық интраперитонеалды химиотерапияны жасалған перитонеальды канцероматозы бар 7 науқастардың мәліметтерін ретроспективті талдау. Отаға көрсеткіштер және емдеу әдісін таңдау мультидисциплинарлы кеңесте талқыланды. Барлық науқастарға максимальды циторедуктивті ота мен гипертермиялық интраперитонеалды химиотерапияны толық циторедукция мақсатымен жасалды. Резекцияға келмейтін және паллиативті ота жасалған науқастар талдауға алынған жоқ. Операциядан кейінгі асқынулар Clavien-Dindo жіктелуі бойынша аңықталды және гипертермиялық интраперитонеалды химиотерапияны байланысты жанама әсерлер Ұлттық обыр интститутының Жанама әсерлердің жалпы терминологиясы критерийлеріне сәйкес жіктелді. Демографиялық, клиникалық және гистопатологиялық мәліметтер талқыланды.

Нәтижелер: Орташа жас 47 (30-62) жасты құрады. Үш науқас әйел жынысты болды. Алғашқы ісікке байланысты колоректалды обыр 3 науқаста, аналық бездер обыры 2 жағдайда, ішперде псевдомиксомасы 2 науқаста болды. Орташа перитонеалды канцероматоз индексі 17 (3-32), орташа ота ұзақтығы 517 (336-710) минутты құрады. Операциядан кейінгі асқынулар мен өлім көрсеткіші сәйкесінше 2 науқаста $(28,5 \%)$ және 1 науқаста $(14,2 \%)$ байқалды. Орташа бақылау уақыты 9,6 айда жалпы өмір сүру мен жалпы рецидивсіз кезең сәйкесінше 85,7\% және 83,3\% құрады. Колоректалды обыры бар бір науқаста (12 айдан кейін) құрсақ арты кеңістігінде рецидив анықталды. Қалған науқастарда рецидивтің белгілері жоқ.

Қортынды: Циторедуктивті ота мен гипертермиялық интраперитонеалды химиотерапияны перитонеальды канцероматозы бар науқастарда емдеуде оң нәтижелер көрсетүде. Әдеби мәліметтермен салыстырғанда емделген науқастар тобында хирургиялық нәтижелер осы аталған ем түрін қолданғанда үміт тұдырады. Перитонеальды канцероматозы емдеудегі қанағаттанарлық нәтиже алу үшін тиянақты операция алдындағы тексеру, науқастардың сәйкес сұрыпталуы және мультидисциплинарлы қаралуы міндетті.

Негізгі сөздер: перитонеалды канцероматоз, циторедуктивті ота, интраперитонеалды химиотерапия

\section{МАКСИМАЛЬНАЯ ЦИТОРЕДУКТИВНАЯ ОПЕРАЦИЯ И ГИПЕРТЕРМИЧЕСКАЯ ИНТРАПЕРИТОНЕАЛЬНАЯ ХИМИОТЕРАПИЯВЛЕЧЕНИИПЕРИТОНЕАЛЬНОГОКАНЦЕРОМАТОЗА:ПЕРВЫЙОПЫТВНЕДРЕНИЯИТЕХНИКА} Ускенбаев Т.А., Керимкулов А.К., Мукажанов А.К., Мамлин М.А., Калиев Р.Б.

Отделение хирургии, Национальный научный центр онкологии и трансплантологии, город Нур-Султан, Республика Казахстан

\section{РЕЗЮМЕ}

Цель: Целью данной статьи служит поделиться опытом внедрения и результатами проведенных максимальных циторедуктивных операций с гипертермической интраперитонеальной химиотерапией у пациентов с перитонеальным канцероматозом с описанием технических деталей операции и освещением текущих литературных данных.

Материалы и методы: Данные 7 пациентов с перитонеальным канцероматозом, которые были пролечены путем максимальных циторедуктивных операций и гипертермической интраперитонеальной химиотерапией в Национальном научном центре онкологии и трансплантологии за период с октября 2016 года по декабрь 2018 года были ретроспективно анализированы. Показания к операции и выбор метода лечения были обсуждены на мультидисциплинарном совете. Всем пациентам выполнена максимальная циторедуктивная операция и гипертермическая интраперитонеальная химиотерапия с целью полной циторедукции. Пациенты с нерезектабельной опухолью и/или, которым произведены палиативные вмешательства исключены из анализа. Периоперационные осложнения классифицировались согласно классифрикации Clavien-Dindo, гипертермическая интраперитонеальная химиотерапия-ассоциированные побочные эффекты классифицировались в соответствии с Критериями Общей Терминологии Побочных Эффектов Национального института рака. Демографические, клинические и гистопатологические данные были анализированы.

Результаты: Средний возраст составил 47 (30-62). Трое пациентов были женского пола. В зависимости от первичной опухоли колоректальный рак был у 3 пациентов, рак яичников - в 2 случаях и 2 пациента - с псевдомиксомой брюшины. Средний индекс перитонеального канцероматоза составил 17 (3-32), средняя длительность операции составила - 517 (366-710) минут. Послеоперационные осложнения и летальность имели место у 2 пациентов $(28,5 \%)$ и у 1 пациента (14,2\%) соответственно. При среднем времени наблюдения в 9,6 месяцев общая выживаемость и общий безрецидивный период составили 85,7\% и 83,3\% соответственно. У одного пациента с колоректальным раком (после 12 месяцев) развился рецидив в забрюшинном пространстве. Остальные пациенты без признаков рецидива заболевания.

Заключение: Циторедуктивная операция с гипертермической интраперитонеальной химиотерапией имеет положительные результаты в лечении пациентов с перитонеальным канцероматозом. В сравнении с литературными данными, хирургические результаты в приведенной серии пациентов, обнадеживающие при применении данного метода лечения. Тщательное предоперационное обследование, соответствующая селекция пациентов и мультидисплинарный подход обязательны для достижения удовлетворительных результатов лечения перитонеального канцероматоза.

Ключевые слова: перитонеальный канцероматоз, циторедуктивная операция, интраперитонеальная химиотерапия

\section{Введение}

Перитонеальный канцероматоз (ПК) наиболее частое клиническое проявление распространенности как опухолей желудочно-кишечного тракта и женских половых органов, так и первичных опухолей брюшины, которое влияет на продолжительность жизни пациентов. Около 15\% пациентов с колоректальным раком (КРР) имеют ПК на момент первичного установления диагноза, продолжительность жизни которых можно продлить до 6 месяцев при проведении паллиативных методов лечения [1, 2]. Spratt $[3,4]$ и Sugarbaker в 80-х годах прошлого века предложили идею рассмотрения ПК как местно-распространенного рака, нежели метастатическое поражение [5]. В настоящее время в опубликованных научных данных максимальная циторедуктивная операция (МЦО) с гипертермической интраперитонеальной химиотерапией (ГИПХ) приводится как основной хирургический метод лечения ПК.

Циторедуктивная операция - это процедура, разработанная Sugarbaker [5], которая включает в себя резекцию нескольких органов и перитонеумэктомию. Цель операции максимально полное удаление опухолевых тканей, органов и/или брюшины без оставления любых видимых опухолевых масс в брюшной полости. Интраперитонеальная химиотерапия направлена на перевод макроскопической 
циторедукции в микроскопическую циторедукцию. При внутрибрюшном применении химиопрепаратов терапевтическая концентрация последнего в брюшной полости может быть достигнута меньшими дозами химиотерапевтических лекарств, что дает возможность получить аналогичный эффект с наименьшими системными побочными действиями. Гипертермия увеличивает эффективность интраперитонеальной химиотерапии путем повышения перитонеального кровотока, прямого цитотоксического воздействия и влияния на окружающую микросреду опухоли [6]. Для достижения успешных результатов в лечении ПК необходимо строгое осуществление трех основных условий: соответствующий отбор пациентов, максимальная циторедукция и периоперационная интраперитонеальная химиотерапия с последующей послеоперационной химиотерапией [7].

Целью данной статьи служит поделиться опытом внедрения и результатами проведенных МЦО с ГИПХ в нашем центре с описанием технических деталей операции и освещением текущих литературных данных.

\section{Материалы и методы}

Ретроспективно проведен анализ ближайших результатов лечения 7 пациентов с ПК, которым была произведена МЦО и ГИПХ в Национальном Научном Центре Онкологии и Трансплантологии (ННЦОТ) с октября 2016 года по декабрь 2018 года. Предоперационное стадирование, а также оценка распространенности ПК проводилась КТ исследованием грудного, абдоминального сегментов и малого таза с оральным и внутривенным контрастным усилением. Всем пациентам определялся уровень опухолевых онкомаркеров в крови. Показания к операции и лечебная стратегия утверждалась на мультидисциплинарном совете. Пациенты - претенденты были отобраны с целью проведения полной циторедукции. Противопоказанием к операции были вовлечение в процесс корня брыжейки тонкой кишки, массивное поражение забрюшинного пространства с вовлечением сосудов, массивное поражение капсулы поджелудочной железы, поражение тонкой кишки, требующей резекции более чем $2 / 3$ от общей ее длины, нерезектабельные метастазы печени или наличие экстра- перитонеальных метастазов, пациенты с общим состоянием $>2$ по Восточной кооперативной группе онкологов (ECOG) и с наличием тяжелых коморбидных состояний, а также пациенты в возрасте 70 лет и старше. Пациенты-претенденты и их родственники были информированы об этапах операции, возможных послеоперационных осложнениях и исходе, возможности формирования стомы (временной/ постоянной) при необходимости, резекции органов с получением письменного согласия. Всем пациентам оценивался нутриционный статус и общее состояние. При необходимости улучшения показателей крови и нутриционного статуса проводилась предоперационная подготовка. Послеоперационные осложнения классифицировались в соответствии с классификацией Clavien-Dindo [8], и ГИПХ-ассоциированные побочные эффекты классифицировались в соответствии с Критериями Общей Терминологии Побочных Эффектов (Common Terminology Criteria for Adverse Events - CTCAE) [9]. Всем пациентам после выписки проводились контрольные КТ исследования и контроль онкомаркеров крови с определенной периодичностью. Рецидивы заболевания и летальность регистрировались. Демографические, клинические и гистопатологические данные были анализированы ретроспективно.

\section{Техника операции}

Всем пациентам проводилась предоперационная антибиотикопрофилактика и катетеризация мочевого пузыря. Повторная инъекция антибиотика проводилась через три часа. Положение пациента на спине. Проводилась средне-срединная лапаротомия и оценка резектабельности. При резектабельном случае срединная рана расширялась вверх до мечевидного отростка и вниз до лона. Резекция круглой связки выполнялась в обязательном порядке. После вскрытия брюшной полости проводилась эвакуация жидкости и муцина при их наличии. Ретракторы раны устанавливались сверху и снизу. Распространенность процесса оценивалась путем подсчета Индекса Перитонеального Канцероматоза (Peritoneal Carcinomatosis Index - PCI), разработанного Sugarbaker (Рисунок 1), с интраоперационным стадированием (Рисунок 1) [10].
Индекс Перитонеального Канцероматоза (РСI)

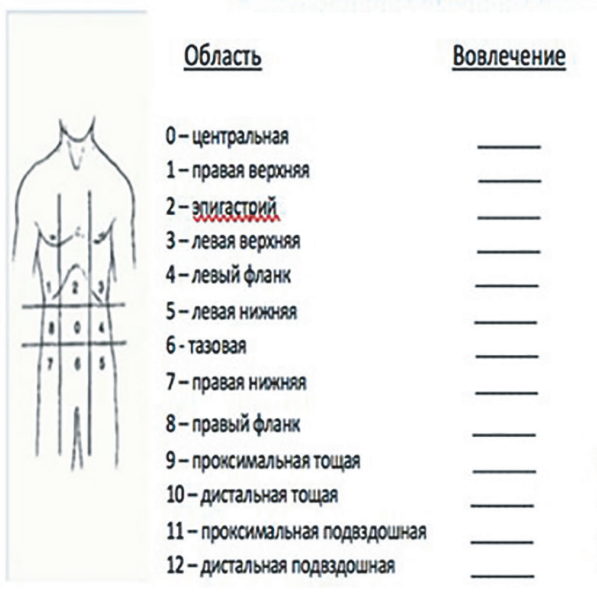

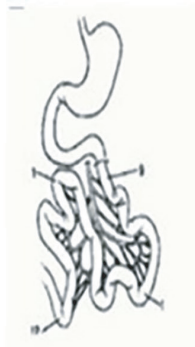

Размер опухоли (LS LSO onpxons orcyctrovet LS1 $\leq 0,5 \mathrm{~cm}$ LS2 $0,5-5,0 \mathrm{~cm}$ LS3 25,0 cси 60 onswe

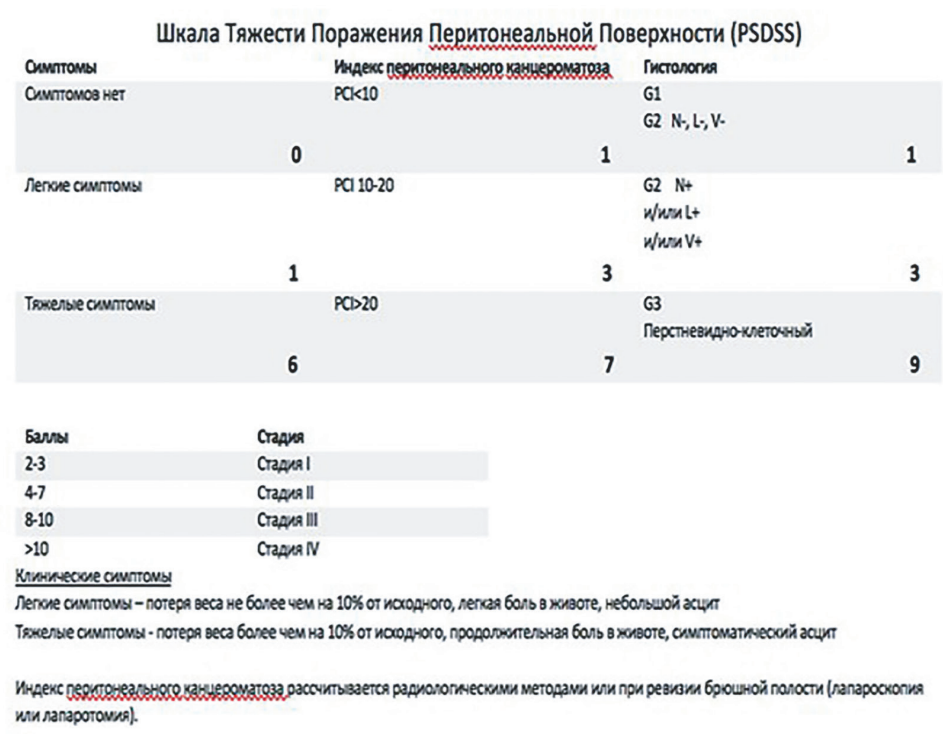

Рисунок 1 - Шкалы, применяемые для определения распространенности перитонеального канцероматоза. Индекс перитонельного канцероматоза, разработанный Sugarbaker (10) и Шкала тяжести поражения перитонеальной поверхности, разработанная Esquivel. 
Агрессивная резекция органов и перитонеумэктомия выполнялась при циторедуктивной операции с целью достижения максимальной макроскопической циторедукции [11]. Максимальность циторедукции (Completeness of Cytoreduction - CC) определяли размером остаточной опухоли: СС 0 - макроскопически видимая опухоль отсутствует, СС 1 - остаточная опухоль размерами $<2,5$ мм, СС 2 - остаточная опухоль размерами от 2,5 мм до 2,5 см, СС 3 - массивная опухоль размерами $>2,5 \mathrm{~cm}$. При ревизии брюшной полости определялись органы и отделы брюшины, требующие резекции и удаления. Оментэктомия проводилась в первую очередь. Стриппинг вовлеченных в процесс участков брюшины выполнялся по методике Sugarbaker. Непораженные области брюшины не удалялись, за исключением при псевдомиксоме брюшины (ПМБ). У пациентов с ПМБ все части париетальной брюшины удалялись в обязательном порядке, вне зависимости от наличия или отсутствия диссеминации. Опухолевые отсевы на поверхности печени удалялись путем стриппинга глиссоновой капсулы. Для достижения максимальной циторедукции и перитонеумэктомии правого поддиафрагмального пространства, производилась полная мобилизация печени. При повреждении диафрагмы проводилось ее восстановление с применением пробы Вальсальвы. Холецистэктомия с диссекцией гепатодуоденальной связки и иссечением малого сальника выполнялась при вовлечении последних в опухолевый процесс. Бурсэктомия требовалась при наличии диссеминатов на поверхности капсулы поджелудочной железы. Левая поддиафрагмальная перитонеумэктомия выполнялась аналогично правой со спленэктомией. При тазовой циторедукции тазовая перитонеумэктомия проводилась c en-bloc резекцией тазовых органов (прямая кишка, матка с придатками, мочевой пузырь). В случаях ПК при раке яичников производилась билатеральная аортоподвздошная лимфодиссекция. Небольшие импланты опухоли на тонкой и толстой кишках, а также на их брыжейках удалялись остро либо путем каутеризации. Некоторые случаи потребовали парциальной резекции желудка или кишечника при массивном опухолевом поражении. Формирование анастомозов выполнялось после проведения ГИПХ. Небольшие дефекты стенок кишечника устранялись незамедлительно. Временное закрытие брюшной полости достигалось путем ушивания раны непрерывным кожным швом. После завершения ГИПХ брюшная полость повторно вскрывалась. Производилось формирование анастомозов. Превентивная илеостомия выполнялась при низких резекциях прямой кишки.

\section{Гипертермическая интраперитонеальная химиотерапия}

После завершения циторедуктивного этапа операции ГИПХ выполнялась закрытым методом. Приводящие катетеры устанавливались в подпеченочное пространство справа, поддиафрагмальное пространство слева, по левому боковому каналу, в малый таз, по правому боковому каналу и под корень мезоколон, отводящие катетеры устанавливались поверхностно над печенью.

После установки температурных датчиков брюшная полость закрывалась путем непрерывного кожного шва. Химиопрепарат добавлялив 3 литраперфузионного раствора, который нагревался до постоянной температуры в 42-43оС, после чего проводилась циркуляция раствора в брюшной полости в течении - 60-100 мин при помощи аппарата для ГИПХ. В 4 случаях в качестве химиотерапевтического препарата применили оксалиплатин 200 мг/м2, у 2 пациентов - митомицин С 20 мг/м2, и в 1 случае - цисплатин 50 мг/ м2 (Таблица II). Во время проведения ГИПХ проводился контроль красной крови, газов крови и коагуляционных факторов крови. После завершения ГИПХ брюшная полость вскрывалась, катетеры удалялись, производилось формирование анастомозов. Дренирование брюшной полости использовали в трех случаях - пациентам, которым проводили резекцию кишечника.

\section{Статистический анализ}

Непрерывные переменные были выражены как средние значения и распределения, категорийные переменные как частота и проценты. Статистический анализ и анализ выживаемости не проводился в связи с ограниченным количеством пациентов.

\section{Результаты}

Четыре пациента были мужского пола, три пациента женского пола (Таблица 1). Средний возраст составил - 47 лет (30-62).

\section{Таблица 1 Характеристика пациентов $(\mathrm{n}=7)$}

\begin{tabular}{ll}
\hline Характеристика & $\mathrm{n}$ \\
\hline Пол & \\
Мужской & 4 \\
Женский & 3
\end{tabular}

\section{Возраст}

$30-40 \quad 2$

41-50 2

$51-60 \quad 2$

$>60-1$

Общее состояние ЕCOG 0

ECOG 1

Патогистологический тип

Муцинозная цистоаденокарцинома яичников 1

Гранулезоклеточная опухоль яичников 1

Аденокарцинома толстой кишки 3

Псевдомиксома брюшины

Заболевание

Первичное 4

Рецидивное 3

Предоперационная химиотерапия Проводилась 5 Не проводилась 2

Среднее значение индекса перитонеального $17(3-32)$ канцероматоза

ECOG - Восточная кооперативная группа онкологов

В зависимости от первичной опухоли КРР был у 3 пациентов, рак яичников - в 2 случаях и 2 пациента - с псевдомиксомой брюшины (ПМБ). Предоперационную 
химиотерапию получили 5 пациентов. Средний PCI составил 17 (3-32). Средняя длительность операции (циторедукция+ГИПХ) составила - 517 (366-710) минут (Таблица 2).

Таблина 2 Характеристика процедуры гипертермической интраперитонеальной химиотерапии (ГИПХ)

\begin{tabular}{ll}
\hline Характеристика & $\mathrm{n}$ \\
\hline Химиотерапевтический агент & 1 \\
Цисплатин & 4 \\
Оксалиплатин & 2 \\
Митомицин С & \\
& \\
Время перфузии (минуты) & \\
60 & 2 \\
100 & 5
\end{tabular}

$\begin{array}{ll}\text { Органы и ткани циторедукции } & 1 \\ \text { Резекция желудка } & 1 \\ \text { Резекция дПк } & 2 \\ \text { Резекция тонкой кишки } & 2 \\ \text { Резекция ободочной кишки } & 2 \\ \text { Низкая передняя резекция прямой кишки } & 1 \\ \text { Резекция мочеточника } & 2 \\ \text { Резекция передней брюшной стенки } & 6 \\ \text { Спленэктомия } & 2 \\ \text { Экстирпация матки с придатками } & 1 \\ \text { Иссечение забрюшинной опухоли } & 4 \\ \text { Перитонеумэктомия тотальная } & 4 \\ \text { Перитонеумэктомия правая поддиафрагмальная } & 1 \\ \text { Перитонеумэктомия левая поддиафрагмальная } & 2 \\ \text { Перитонеумэктомия тазовая } & 3 \\ \text { Илеостомия временная } & 3\end{array}$

Максимальность циторедукции

CC 0

CC 1

Средняя длительность операции (минуты)

$517(366-710)$

Средний объем кровопотери (мл)

$1128(700-1700)$

Перитонеумэктомия всех областей проведена у 4 пациентов, правая поддиафрагмальная перитонеумэктомия у 1 пациента, левая поддиафрагмальная перитонеумэктомия - в 2 случаях, тазовая перитонеумэктомия - у 3 пациентов. Резекция желудка выполнена у 1 пациента, резекция ДПК - у 1 пациента, резекция тонкой кишки - в 2 случаях, резекция толстой кишки - в 2 случаях, нижняя передняя резекция прямой кишки - у 2 пациентов, экстирпация матки с придатками - у 2 пациентов, резекция передней брюшной стенки - у 2 пациентов, иссечение опухоли забрюшинного пространства - в 1 случае, резекция мочеточника - в 1 случае. Формирование гастроинтестинальных анастомозов произведена у 3 пациентов. Временная илеостомия сформирована у 3 пациентов. Максимальная циторедукция - СС 0 - достигнута у 5 пациентов, СС 1 - в 2 случаях.
Средний объем кровопотери составил 1128 (700-1700) мл. Среднее пребывание больного в стационаре было 30 (10-64) к/д.

Послеоперационные осложнения имели место у 2 пациентов (28,5\%) (Таблица 3$)$.

\section{Таблица 3}

Хирургический исход

\begin{tabular}{ll} 
Характеристика & $\mathrm{n}$ \\
\hline Среднее пребывание в стационаре (к/д) & 30 (10-64) \\
Среднее время наблюдения (месяцы) & 9,6 (3-26) \\
Послеоперационные осложнения & \\
По Clavien - Dindo: Степень III & 2 \\
$\quad$ Степень IV $\quad$ Степень V & 1 \\
& 1 \\
Перфорация желудка & 1 \\
Несостоятельность гастроэнтероанастомоза & 1 \\
Несостоятельность швов ДПК & 1 \\
Сепсис & 1 \\
Исход пребывания в стационаре & \\
Выписаны & \\
Летальный исход & 6 \\
Рецидив заболевания & 1 (14,2\%)
\end{tabular}

В первом случае у пациента с ПМБ, которому произведена резекция желудка, низкая резекция прямой кишки, произошла перфорация желудка на 7 сутки после операции, что потребовало реоперации. В последующем у данного пациента развилась несостоятельность гастроэнтероанастомоза. Пациент умер на 59 сутки от сепсиса ипрогрессирующей полиорганной недостаточности. Во втором случае у пациента с раком сигмовидной кишки, которому произведена резекция ДПК, субтотальная колэктомия, резекция тонкой кишки, произошла несостоятельность швов ДПК. Пациент реоперирован и выписан на 35 сутки. Побочные действия, связанные с ГИПХ не отмечены. Среднее время наблюдения после выписки составило 9,6 месяцев (3-26). В одном случае у пациентки с раком яичников через 3 месяца после операции сформировалась серома левого поддиафрагмального пространства, которое дренировано под УЗ наведением. Рецидив заболевания наблюдался у одного пациента с КРР. Через год после операции у пациента отмечен повторный рост опухоли в забрюшинном пространстве. Пациенту проведено иссечение забрюшинной опухоли. У остальных пациентов признаков рецидива заболевания не отмечено. 5 пациентам после операции проведены курсы адъювантной химиотерапии. Общая выживаемость составила 85,7\%, общий безрецидивный период составил 83,3\% при среднем времени наблюдении в 9,6 месяцев.

\section{Обсуждение}

Исследования с крупными сериями пациентов [12-16] и рандомизированные исследования [17-21], посвящённые циторедуктивным операциям с ГИПХ и опубликованные в недавние годы, показывают, что данный подход лечения ПК продлевает общую продолжительность жизни у отборной группы пациентов.

Основываясь на результатах этих исследований, циторедуктивные операции и интраперитонеальная 
химиотерапия все больше и больше рассматривается как опция лечения ПК. В ННЦОТ циторедуктивные операции с ГИПХ внедрены в 2016 году. Малое количество пролеченных пациентов, короткий период наблюдения за больными, невозможность проведения анализа выживаемости ограничивают наше исследование. Ранние результаты нашей серии лечения пациентов, которым проведены операции в единственном центре, представлены с литературным обзором, в связи с чем обнадеживают нас на дальнейшее исследование данного метода лечения.

Необходимость мультиорганной резекции, более длительное время операции и интраперитонеальная химиотерапия, наряду с предоперационной химиотерапией, предыдущими абдоминальными операциями и плохим общим состоянием включают пациентов с ПК в группу с высоким риском развития осложнений. По данным литературы общий показатель осложнений после МЦО с ГИПХ составляет 12-56\%, периоперационная летальность - 0-12\% [22-25]. Частота осложнений зависит от степени диссеминации опухолевого процесса, объема циторедукции, количества резецированных органов, возраста, периоперационной кровопотери и длительности операции [26, 27]. Другой значимый фактор частоты развития осложнений по опубликованным данным является кривая обучения (>200 операций) и опыт организации [28]. ГИПХ-ассоциированная токсичность наиболее важная причина осложнений и летальности у таких пациентов. Выбор препаратов, применяемых при ГИПХ и их дозировка должны основываться на тщательном предоперационном обследовании функции почек и костного мозга. В нашей серии пациентов осложнения, которые развились у 2 $(28,5 \%)$ пациентов имели тяжелое течение (степень 3-5). У пациента, которому была проведена обширная циторедукция с резекцией желудка и низкой передней резекцией прямой кишки по поводу псевдомиксомы брюшины, произошла перфорация желудка, с последующим развитием несостоятельности гастроэнтероанастомоза, что в свою очередь привело к развитию сепсиса и летального исхода. При оценке распространённости диссеминации РСI у данного пациента составил 32. Учитывая гистологический вариант опухоли-псевдомиксома брюшины, средний возраст пациента, хорошее общее состояние пациента, несмотря на высокий PCI, решено было провести агрессивную операцию. Осложнения в нашей серии операций сопоставимы с литературными данными. Однако летальность в наших случаях немного выше. В нашем понимании недостаточный опыт и неоправданный отбор пациентов играют решающую роль в получении неудовлетворительного результата. В исследовании с участием 100 пациентов Moran и др. [29] сообщили о частоте летальности в $18 \%$ среди первых 33 пациентов, 3\% среди второй группы из 33 пациентов и $3 \%$ у последних 33 пациентов.

Распространенность процесса в брюшной полости и объем операции, требующий достижения максимальной циторедукции наиболее значимые прогностические факторы, влияющие как на ближайшие послеоперационные исходы, так и на отдаленные онкологические результаты. Отбор пациентов - претендентов на МЦО с ГИПХ является наиболее сложным процессом, которое требует оценку множественных факторов, касающихся и пациентов, и самого опухолевого процесса. Piso и другие [30] перечислили следующие факторы, влияющие на принятие решения: опухоль-ассоциированные факторы первичная опухоль, степень дифференцировки, наличие метастатического поражения, вовлечение парааортальных лимфоузлов, РСI, вовлечение тонкой кишки, малого сальника, билиарная или мочеточниковая обструкция и ответ на предыдущую химиотерапию; другие факторы - общее состояние пациентов, коморбидные состояния, кривая обучения, прогнозируемое послеоперационное качество жизни и мультидисциплинарный подход. Диагностическая лапароскопия и КТ наиболее часто используемые методы диагностики, применяемые при принятии решения и отбора пациентов. Среди всех параметров максимальность циторедукции, объем опухоли (PCI) и ее степень дифференцировки, как было отмечено в различных исследованиях, наиболее значимые независимые прогностические факторы в развитии осложнений и выживаемости. Интраоперационная стадировка и определение PCI как указал Sugarbaker наиболее общие методы прогнозирования максимальности циторедукции (Рисунок 1). Шкала тяжести поражения перитонеальной поверхности (PSDSS), описанная Esquivel [31], более расширенная система оценки, которая включает в себя клинические, радиологические и гистоморфологические параметры. В этой шкале симптомы пациентов (потеря веса, асцит, боли в животе, непроходимость кишечника), радиологические данные PCI и первичная гистоморфологическая особенность опухоли (степень дифференцировки, вовлечение лимфатических узлов, лимфатическая/венозная инвазия, перстневидно-клеточный рак) указываются в баллах, сумма которых определяет стадию заболевания (Рисунок 1). Эта система стадирования показывает взаимосвязь с отдаленными онкологическими результатами у пациентов с КРР и ПМБ, которым была проведена МЦО с ГИПХ, и принята как достоверный метод селекции пациентов на лечение [31].

Компьютерная томография и магнитно-резонансная томография применялись для диагностики и стадирования ПК у наших больных. Однако, радиологические находки перед операцией могут предоставить неадекватную информацию при селекции пациентов. Диагностическая лапароскопия или лапаротомия является основным методом определения резектабельности и выбора метода лечения. Лапароскопия с недавних пор используется не только с диагностической целью, но и для проведения циторедукции с ГИПХ. Этот достоверный метод диагностики наличия ПК позволяет выявлять нерезектабельные случаи перед проведением циторедукции. Несмотря на это необходимо учитывать, что этот метод может привести к недооценке или переоценке распространенности заболевания. Пациентам, которым планируется лапароскопия, должно проводится тщательная оценка забрюшинного пространства, корня брыжейки тонкой кишки, инвазии поджелудочной железы при помощи КТ перед операцией. Диагностическая лапароскопия особенно полезна при обнаружении милиарных поражений серозы тонкой кишки, которые не выявляются при КТ или МРТ. У нашей серии пациентов для определения резектабельности и выбора метода лечения использовали диагностическую лапаротомию.

Имеются несколько исследований, которые показали положительноевоздействие МЦО сГИПХ на онкологические исходы пациентов с КРР (Таблица 4). Несмотря на многочисленные инновации, такие как таргетная терапия, результаты системной химиотерапии, применяемой как единственный метод лечения, остаются неутешительными в сравнении с МЦО и ГИПХ [32]. Полнота цироредукции и значение РCI наиболее важные прогностические факторы, 


\begin{tabular}{|c|c|c|c|c|c|c|}
\hline Автор, Центр, Год & Дизайн исследования & N пациентов & $\begin{array}{l}\text { Максима-льность } \\
\text { циторедукции (\%) }\end{array}$ & $\begin{array}{l}\text { Внутри-брюшная } \\
\text { химиотерапия }\end{array}$ & \begin{tabular}{|l} 
Среднее \\
наблюдения \\
(месяцы)
\end{tabular} & $\begin{array}{l}\text { Медиана } \\
\text { выживае-мости } \\
\text { (месяцы) }\end{array}$ \\
\hline Verwaal, Амстердам, 2003 & Рандомизи-рованное & 105 & * & ГИПХ & 21,6 & 22,3 \\
\hline $\begin{array}{l}\text { Glehen, многоцентровое, } \\
2004,\end{array}$ & Ретро-спективное & 506 & 53,5 & гипХ/ & & \\
\hline РПИХ & 53 & 19,2 & & & & \\
\hline Da Silva, Вашингтон, 2006 & Ретро-спективное & 70 & 100 & гипХ/ & & \\
\hline РПИХ & 46,5 & 33 & & & & \\
\hline Levine, Уэйк Форест, 2007 & Ретро-спективное & 133 & * & ГИПХ & 55,4 & 16,4 \\
\hline Shen, Уэйк Форест, 2008 & Ретро-спективное & 121 & 45 & ГИПХ & 86 & 34 \\
\hline Elias, Франция, 2009 & Ретро-спективное & 48 & * & ГИПХ & 63 & 62,7 \\
\hline Elias, Франция, 2010 & Ретро-спективное & 523 & 84 & гипХ/ & & \\
\hline РПИХ & 45 & 30,1 & & & & \\
\hline Quenet, Франция, 2011 & Ретро-спективное & 146 & 90 & ГИПХ & 48,5 & 41 \\
\hline
\end{tabular}

ГИПХ - гипертермическая интраперитонеальная химиотерапия; РПИХ - ранняя послеоперационная интраперитонеальная химиотерапия; * - нет данных

определяющие продолжительность жизни. Роль ГИПХ у пациентов, которым R0 резекция не может быть достигнута, противоречива. C другой стороны, множественные исследования, которые проводили сравнение МЦО без применения химиотерапии с МЦО и ГИПХ, показали положительный эффект при применении ГИПХ [33].

Средняя выживаемость пациентов с раком яичников с ПК при традиционном лечении составляет 12-25 месяцев [34]. Положительные результаты исследований предлагают использовать интраперитонеальную химиотерапию у пациентовсракомяичниковпримаксимальнойциторедукции, и данный метод рассматривается как стандартный подход лечения при III стадии рака яичников. Исследования, проведенные в области МЦО с ГИПХ у пациентов с раком яичников, являются не рандомизированными контрольными исследованиями. Однако, многие обсервационные исследования с крупными сериями пациентов отметили 2264 месячную медиану выживаемости и 12-66\% 5-летнюю общую выживаемость при применении МЦО с ГИПХ [35]. В Таблице 5 представлены важные исследования и результаты в области МЦО с ГИПХ при раке яичников с ПК.

Таблица 5 Результаты некоторых исследований в области циторедуктивной операции и интраперитонеальной химиотерапии при раке яичников с перитонеальным канцероматозом

\begin{tabular}{|c|c|c|c|c|c|}
\hline Автор, Центр, Год & Дизайн исследования & N пациентов & $\begin{array}{l}\text { Максимальность } \\
\text { циторедукции (\%) }\end{array}$ & $\begin{array}{l}\text { Среднее наблюдения } \\
\text { (месяцы) }\end{array}$ & $\begin{array}{l}\text { Медиана } \\
\text { выживаемости } \\
\text { (месяцы) }\end{array}$ \\
\hline Ryu, Сеул, 2004 & Ретроспективное & 57 & 84 & 47 & $49^{* *}$ \\
\hline Cotte, Франция, 2007 & Ретроспективное & 81 & 56 & 47 & 28 \\
\hline Guardiola, Франция, 2009 & Ретроспективное & 47 & $*$ & 23 & $14^{* *}$ \\
\hline Pavlov, ьелград, 2009 & Ретроспективное & 56 & 93 & 60 & 38 \\
\hline Helm, многоцентровое США, 2010 & Ретроспективное & 83 & 58 & 18 & 30 \\
\hline Parson, Уэйк Форест, 2011 & Ретроспективное & 51 & 40 & 98 & 29 \\
\hline Deraco, Милан, 2011 & Ретроспективное & 26 & 58 & 25 & $30^{* *}$ \\
\hline Bakrin, Франция, 2013 & Ретроспективное & 473 & 75 & 40 & $35-45^{* * *}$ \\
\hline
\end{tabular}

ГИПХ - гипертермическая интраперитонеальная химиотерапия; РПИХ - ранняя послеоперационная интраперитонеальная химиотерапия; * нет данных; ** - без рецидивная выживаемость; *** - пациенты с местно-расппространенным и рецидивным процессом

В нашем опыте было два пациента с раком яичников, которым проведены МЦО и ГИПХ с полнотой циторедукции СC 0. За период наблюдения рецидива заболевания не отмечено. Обапациента получили системную химиотерапию после операции.

Псевдомиксома брюшины группа опухолей поверхности брюшины с наиболее благоприятным прогнозом. По последним данным отмечена 10-летняя выживаемость в группе, которым выполнены МЦО с ГИПХ. Многоцентровое исследование с 2296 пациентами, которые пролечены путем МЦО и ГИПХ, показало медиану выживаемости в 196 месяцев, а 10-летняя общая выживаемость составила $63 \%$ [36]. В аналогичном исследовании средний РСІ был 20, и частота достижения полной циторедукции составила 83\%. Независимыми негативными прогностическими факторами общей выживаемости были адъювантная химиотерапия в анамнезе, большие осложнения, СС 2/СС 3 циторедукция, МЦО без ГИПХ, высокий РСІ и возраст. В этой конкретной группе пациентов PCI и отсутствие возможности достижения $\mathrm{R} 0$ резекции не являются противопоказанием к ГИПХ, и в отличие от других гастроинтестинальных источников ПК, рекомендуется удаление всех областей брюшины вне зависимости от наличия или отсутствия диссеминации. Псевдомиксома брюшины заболевание, которое имеет наиболее полный ответ к лечению вне зависимости от 
PCI. В нашей серии было 2 пациента с ПМБ: один пациент умер в ближайшем послеоперационном периоде в связи с тяжелыми послеоперационными осложнениями, второй пациент наблюдается в течение 26 месяцев после МЦО с ГИПХ без признаков рецидива заболевания.

Множество химиотерапевтических препаратов, применяемых в данном методе лечения были исследованы. К ним входят различные препараты такие как цисплатин, митомицин $\mathrm{C}$, паклитаксел, липосомальный доксорубицин, оксалиплатин, карбоплатин, доцетаксел и иринотекан, которые, в частности, имеют повышенную активность при высокой температуре. В настоящее время цисплатин и митомицин С наиболее часто, раздельно либо в комбинации используемые препараты при раке яичников с ПК, цисплатин, митомицин С и оксалиплатин - при КРР, митомицин С - при ПМБ, цисплатин и митомицин С - при раке желудка [37].

\section{Заключение}

Циторедуктивная операция с ГИПХ увеличивает выживаемость пациентов с ПК. Максимальная циторедукция наиболее важный критерий достижения успеха при данном подходе лечения. Множественные факторы, как со стороны пациента, так и особенности самого опухолевого процесса, влияют на принятие решения. Правильная селекция пациентов и опыт центра важные факторы, влияющие на хирургические результаты и частоту выживаемости.

Disclosures: There is no conflict of interest for all authors

\section{Литература}

1. Spratt JS, Adcock RA, Sherrill W, Travathen S. Hyperthermic peritoneal perfusion system in canines. Cancer Res. 1980; 40:253-255.

2. Spratt JS, Adcock RA, Muskovin M, Sherrill W, McKeown J. Clinical delivery system for intraperitoneal hyperthermic chemotherapy. Cancer Res. 1980; 40:256-260. https://doi.org/10.5465/ambpp.1980.4976211

3. Chu DZ, Lang NP, Thompson C, Osteen PK, Westbrook KC. Peritoneal carcinomatosis in nongynecologic malignancy. A prospective study of prognostic factors. Cancer. 1989; 63:364-367. https://doi.org/10.1002/1097-0142(19890115)63:2<364::AIDCNCR2820630228>3.0.CO;2-V

4. Jayne D, Fook S, Seow-Choen F. Peritoneal carcinomatosis from colorectal cancer. Br J Surg. 2002; 89:1545-1550. https://doi. org/10.1046/j.1365-2168.2002.02274.x

5. Sugarbaker PH, Gianola FJ, Speyer JL Wesley R, Barofsky I, Meyers CE. Prospective randomized trial of intravenous vs intraperitoneal 5-FU in patients with advanced primary colon or rectal cancer. Semin Oncol. 1985; 12:101-111.

6. Kampinga HH, Dynlacht JR, Dikomey E. Mechanism of radiosensitization by hyperthermia ( $>$ or $=43$ degrees C) as derived from studies with DNA repair defective mutant cell lines. Int J Hyperthermia. 2004; 20:131-139. https://doi.org/10.1080/02656730310001 627713

7. Esquivel J, Elias D, Baratti D, Kusamura S, Deraco M. Consensus statement on the loco regional treatment of colorectal cancer with peritoneal dissemination. J Surg Oncol. 2008; 98:263-267. https://doi.org/10.1002/jso.21053

8. Dindo D, Demartines N, Clavien PA. Classification of surgical complications: a new proposal with evaluation in a cohort of 6336 patients and results of a survey. Ann Surg. 2004; 240:205-213. https://doi.org/10.1097/01.sla.0000133083.54934.ae

9. National Cancer Institute (NCI)/National Institute of Health (NIH). Common Terminology Criteria for Adverse Events (CTCAE), version 3.0. https://webapps.ctep.nci.nih.gov/webobjs/ctc/webhelp/welcome_to_ctcae.htm

10. Jacquet P, Sugarbaker PH. Current methodologies for clinical assessment of patients with peritoneal carcinomatosis. J Exp Clin Cancer Res. 1996; 15:49-58. https://doi.org/10.1007/978-1-4613-1247-5_23

11. An overview of peritonectomy. Visceral Resections, and Perioperative Chemotherapy for Peritoneal Surface Malignancy. «Cytoreductive Surgery \& Perioperative Chemotherapy for Peritoneal Surface Malignancy, textbook and Video Atlas, Ed. Paul H. Sugarbaker, CineMed Publishing. Inc. 2013; 1-30.

12. Shen P, Hawksworth J, Lovato J, Loggie BW, Geisinger KR, Fleming RA, et al. Cytoreductive surgery and intraperitoneal hyperthermic chemotherapy with mitomycin C for peritoneal carcinomatosis from nonappendiceal colorectal carcinoma. Ann Surg Oncol. 2004; 11:178-186. https://doi.org/10.1245/ASO.2004.05.009

13. Levine EA, Stewart JH, Russell GB, Geisinger KR, Loggie BL, Shen P. Cytoreductive surgery and intraperitoneal hyperthermic chemotherapy for peritoneal surface malignancy: experience with 501 procedures. J Am Coll Surg. 2007; 204:943-945. https://doi. org/10.1016/j.jamcollsurg.2006.12.048

14. Verwaal VJ, van Ruth S, Witkamp A, Boot H, van Slooten G, Zoetmulder FA. Longterm survival of peritoneal carcinomatosis of colorectal origin. Ann Surg Oncol. 2005; 12:65-71. https://doi.org/10.1007/s10434-004-1167-z

15. Da Silva RG, Sugarbaker PH. Analysis of prognostic factors in seventy patients having a complete cytoreduction plus perioperative intraperitoneal chemotherapy for carcinomatosis from colorectal cancer. J Am Coll Surg. 2006; 203:878-886. https://doi.org/10.1016/j. jamcollsurg.2006.08.024

16. Yan TD, Morris DL. Cytoreductive surgery and perioperative intraperitoneal chemotherapy for isolated colorectal peritoneal carcinomatosis: experimental therapy or standard of care? Ann Surg. 2008;248:829-835.https://doi.org/10.1097/SLA.0b013e31818a15b5

17. Glehen O, Kwiatkowski F, Sugarbaker PH, Elias D, Levine EA, De Simone M, et al. Cytoreductive surgery combined with perioperative intraperitoneal chemotherapy for the management of peritoneal carcinomatosis from colorectal cancer: a multiinstitutional study. $J$ Clin Oncol. 2004; 22:3284-3292. https://doi.org/10.1200/JCO.2004.10.012

18. Elias D, Gilly F, Boutitie F, Quenet F, Bereder JM, Mansvelt B, et al. Peritoneal colorectal carcinomatosis treated with surgery and perioperative intraperitoneal chemotherapy: retrospective analysis of 523 patients from a multicentric French study. J Clin Oncol. 2010; 28:63-68. https://doi.org/10.1200/JCO.2009.23.9285

19. Chua TC, Morris DL, Esquivel J. Impact of the peritoneal surface disease severity score on survival in patients with colorectal cancer peritoneal carcinomatosis undergoing complete cytoreduction and hyperthermic intraperitoneal chemotherapy. Ann Surg Oncol. 2010 17:1330-1336. https://doi.org/10.1245/s10434-009-0866-x 
20. Cavaliere F, De Simone M, Virz. S, Deraco M, Rossi CR, Garofalo A, et al. Prognostic factors and oncologic outcome in 146 patients with colorectal peritoneal carcinomatosis treated with cytoreductive surgery combined with hyperthermic intraperitoneal chemotherapy: Italian multicenter study S.I.T.I.L.O. Eur J Surg Oncol. 2011; 37:148-154. https://doi.org/10.1016/j.ejso.2010.10.014

21. Glehen O, Gilly FN, Boutitie F, Bereder JM, Quenet F, Sideris L, et al. French Surgical Association. Toward curative treatment of peritoneal carcinomatosis from nonovarian origin by cytoreductive surgery combined with perioperative intraperitoneal chemotherapy: a multiinstitutional study of 1,290 patients. Cancer. 2010; 116:5608-5618. https://doi.org/10.1002/cncr.25356

22. Di Miceli D, Alfieri S, Caprino P, Menghi R, Quero G, Cina C, et al. Complications related to hyperthermia during hyperthermic intraoperative intraperitoneal chemotherapy (HIPEC) treatment. Do they exist? Eur Rev Med Pharmacol Sci. 2012; 16:737-742.

23. Canda AE, Sokmen S, Terzi C, Arslan C, Oztop I, Karabulut B, et al. Complications and toxicities after cytoreductive surgery and hyperthermic intraperitoneal chemotherapy. Ann Surg Oncol. 2013; 20:1082-1087. https://doi.org/10.1245/s10434-012-2853-x

24. Roviello F, Marrelli D, Neri A, Cerretani D, de Manzoni G, Pedrazzani C, et al. Treatment of peritoneal carcinomatosis by cytoreductive surgery and intraperitoneal hyperthermic chemoperfusion (IHCP): Postoperative outcome and risk factors for morbidity. World J Surg. 2006; 30:2033-2040. https://doi.org/10.1007/s00268-006-0038-0

25. Chua TC, Yan TD, Saxena A, Morris DL. Should the treatment of peritoneal carcinomatosis by cytoreductive surgery and hyperthermic intraperitoneal chemotherapy still be regarded as a highly morbid procedure?: A systematic review of morbidity and mortality. Ann Surg. 2009; 249:900-907. https://doi.org/10.1097/SLA.0b013e3181a45d86

26. Kusamura S, Younan R, Baratti D, Costanzo P, Favaro M, Gavazzi C, et al. Cytoreductive surgery followed by intraperitoneal hyperthermic perfusion: analysis of morbidity and mortality in 209 peritoneal surface malignancies treated with closed abdomen technique. Cancer. 2006; 106:1144-1153. https://doi.org/10.1002/cncr.21708

27. Glehen O, Osinsky D, Cotte E, Kwiatkowski F, Freyer G, Isaac S, et al. Intraperitoneal chemohyperthermia using a closed abdominal procedure and cytoreductive surgery for the treatment of peritoneal carcinomatosis: morbidity and mortality analysis of 216 consecutive procedures. Ann Surg Oncol. 2003; 10:863-869. https://doi.org/10.1245/ASO.2003.01.018

28. Andrasson H, Lorant T, P.hlman L, Graf W, Mahteme H. Cytoreductive surgery plus perioperative intraperitoneal chemotherapy in pseudomyxoma peritonei: aspects of the learning curve. Eur J Surg Oncol. 2014; 40:930-936. https://doi.org/10.1016/j.ejso.2014.03.001

29. Moran BJ. Decision-making and technical factors account for the learning curve in complex surgery. J Public Health. 2006; 28:375378. https://doi.org/10.1093/pubmed/fdl048

30. Piso P, Glockzin G, von Breitenbuch P, Sulaiman T, Popp F, Dahlke M, et al. Patient selection for a curative approach to carcinomatosis. Cancer J. 2009; 15:236 242. https://doi.org/10.1097/PPO.0b013e3181a58f30

31. Esquivel J, Lowy AM, Markman M, Chua T, Pelz J, Baratti D, et al. The American Society of Peritoneal Surface Malignancies (ASPSM) multiinstitution evaluation of the Peritoneal Surface Disease Severity Score (PSDSS) in 1,013 patients with colorectal cancer with peritoneal carcinomatosis. Ann Surg Oncol. 2014; 21:4195-4201. https://doi.org/10.1245/s10434-014-3798-Z

32. Klaver YL, Lemmens VE, Creemers GJ, Rutten HJ, Nienhuijs SW, de Hingh IH. Population-based survival of patients with peritoneal carcinomatosis from colorectal origin in the era of increasing use of palliative chemotherapy. Ann Oncol. 2011; 22:2250-2256. https:// doi.org/10.1093/annonc/mdq762

33. Elias D, Lefevre JH, Chevalier J, Brouquet A, Marchal F, Classe JM, et al. Complete cytoreductive surgery plus intraperitoneal chemohyperthermia with oxaliplatin for peritoneal carcinomatosis of colorectal origin. J Clin Oncol. 2009; 27:681-685. https:/doi. org/10.1200/JCO.2008.19.7160

34. Bijelic L, Jonson A, Sugarbaker PH. Systematic review of cytoreductive surgery and heated intraoperative intraperitoneal chemotherapy for treatment of peritoneal carcinomatosis in primary and recurrent ovarian cancer. Ann Oncol. 2007; 18:1943-1950. https://oi. org/10.1093/annonc/mdm137

35. Deraco M, Baratti D, Laterza B, Balestra MR, Mingrone E, Macr. A, et al. Advanced cytoreduction as surgical standard of care and hyperthermic intraperitoneal chemotherapy as promising treatment in epithelial ovarian cancer. Eur J Surg Oncol. 2011; 37:4-9. https:// doi.org/10.1016/j.ejso.2010.11.004

36. Moran B, Baratti D, Yan TD, Kusamura S, Deraco M. Consensus statement on the loco-regional treatment of appendiceal mucinous neoplasms with peritoneal dissemination (pseudomyxoma peritonei). J Surg Oncol .2008; 98:277-282. https://doi.org/10.1002/jso.21054

37. Van der Speeten K, Stuart OA, Sugarbaker PH. Pharmacokinetics and pharmacodynamics of perioperative cancer chemotherapy in peritoneal surface malignancy. Cancer J. 2009; 15:216-224. https://doi.org/10.1097/PPO.0b013e3181a58d95

How to cite this article: Talgat Uskenbayev, Altay Kerimkulov, Adilbek Mukazhanov, Meiram Mamlin, Rimbay Kaliyev. Cytoreductive surgery and hyperthermic intraperitoneal chemotherapy for treatment of peritoneal carcinomatosis: our initial experience of implementation and detailed technique [in Russian]. J Clin Med Kaz. 2019; 2(52):50-58 